\title{
PENGEMBANGAN KARIR TERHADAP INTENSI TURNOVER PADA KARYAWAN GENERASI MILENIAL
}

\author{
Irma Suwarning Dyastuti ${ }^{1}$, Sarsono ${ }^{2}$ \\ Fakultas Psikologi Universitas Mercu Buana Yogyakarta \\ Email: ${ }^{1}$ irma.widyastuty@gmail.com, ${ }^{2}$ sarsono41@gmail.com
}

C2018 -JPT Fakultas Psikologi Universitas Negeri Makassar. Ini adalah artikel dengan

akses terbuka di bawah licenci CC BY-NC-4.0 (https://creativecommons.org/licenses/by-nc/4.0/ ).

\begin{abstract}
ABSTRAK
Dibalik potensi sumber daya manusia yang dimiliki, perusahaan di indonesia memiliki tantangan dalam mengelola sumber daya manusia khususnya generasi $Y$ atau milenial. Semakin meningkatnya pertumbuhan dan perkembangan perusahaan di Indonesia berdampak positif bagi masyarakat dengan semakin melebarnya peluang kerja sehingga akan mengurangi tingkat pengangguran. Namun hal ini akan berakibat semakin tinggi persaingan antar perusahaan. Hal tersebut menyebabkan perusahaan yang ingin bertahan dalam persaingan menuntut karyawannya untuk dapat memberikan kontribusi maksimal bagi perusahaan tempatnya bekerja. Tujuan penelitian ini adalah untuk mengetahui apakah pengembangan karir berperan penting bagi intensi turnover pada karyawan generasi milenial di PT. TEY. Metode yang digunakan dalam penelitian ini adalah metode observasi dan wawancara serta memberikan kuisioner kepada subjek penelitian, subjek penelitian dalam penelitian ini adalah karyawan generasi milenial di PT TEY sebanyak 95 orang. Hasil penelitian ini menunjukkan bahwa pengembangan karir berperan penting bagi karyawan
\end{abstract}

Kata kunci : Intensi Turnover, Karyawan generasi milenial

\begin{abstract}
Behind the potential of human resources owned, companies in Indonesia have challenges in managing human resources, especially generation $Y$ or millennial. The increasing growth and development of companies in Indonesia has a positive impact on society by widening employment opportunities so that it will reduce the unemployment rate. But this will result in higher competition between companies. This causes companies that want to survive in the competition require their employees to be able to make a maximum contribution to the company where they work. The purpose of this study is to determine whether career development plays an important role for turnover intentions in millennial generation employees at PT. TEY The method used in this study is the method of observation and interviews as well as giving questionnaires to research subjects, research subjects in this study are millennial generation employees at PT TEY as many as 95 people. The results of this study indicate that career development plays an important role for employees
\end{abstract}

Keywords: Turnover Intentions, Millennial Generation Employees 


\section{PENDAHULUAN}

Sumber daya manusia dipandang sebagai aset perusahaan yang penting, karena manusia merupakan sumber daya yang dinamis dan selalu dibutuhkan dalam setiap proses produksi barang maupun jasa (Dessler, 2008). Perusahaan harus dapat mempertahankan karyawan selama mungkin, terlebih bila karyawan tersebut membawa dampak yang positif bagi perusahaan. Keinginan berpindah seseorang terkait erat dengan peluang karier, kepuasan gaji, kepuasan kerja, hubungan kerja,dan lingkungan kerja, serta beban kerja (Zeffane, 1994).

Pergantian karyawan merupakan persoalan yang penting bagi perusahaan dan karyawan. Dari sudut pandang perusahaan, pergantian karyawan dapat memberikan gambaran mengenai biaya yang tidak sedikit menyangkut nilai perekrutan, pelatihan dan biaya yang telah dikeluarkan untuk mengatasi pergantian karyawan dan berbagai biaya tidak langsung seperti kehilangan karyawan yang telah mengerti tentang berbagai pekerjaan dalam perusahaan tersebut. Dari sudut pandang karyawan, pergantian karyawan dapat menimbulkan konsekuensi positif dan atau negative (wahyuni, 2014). Mondy (2008) menegaskan bahwa manusia adalah sumber daya yang sangat penting dalam bidang industri dan organisasi, oleh karena itu pengelolaan sumber daya mencakup penyediaan tenaga kerja yang bermutu, mempertahankan kualitas dan mengendalikan biaya ketenagakerjaan. Disamping sumber daya alam dan sumber daya modal, sumber daya manusia juga memiliki peran yang penting guna mencapai tujuan dan kesuksesan perusahaan.

Menurut De Meuse et al. (2010), terdapat empat generasi angkatan kerja dalam perusahaan, yaitu : matures yang lahir antara tahun 1920 hingga 1939, Boomers lahir tahun 1940 hingga 1959, Xers lahir tahun 1960 hingga 1979 dan Generation $Y$ atau milenial yang lahir tahun 1980 hingga akhir tahun 2000. Generasi Y dikenal dengan sebutan generasi millenial atau millennium, ungkapan generasi $\mathrm{Y}$ mulai dipakai pada editorial koran besar Amerika Serikat pada Agustus 1993. Generasi ini banyak menggunakan teknologi komunikasi instan seperti email, SMS, instant messaging dan media sosial seperti facebook dan twitter, dengan kata lain generasi Y adalah generasi yang tumbuh pada era internet booming (Lyons, 2004). Berdasarkan definisi tersebut dapat ditarik kesimpulan bahwa generasi milenial adalah generasi yang lahir diantara tahun 1980-2000 saat 
terjadi kemajuan teknologi yang pesat. Jika dilihat dari kelompok umur, generasi milenial merupakan generasi yang saat ini berusia dikisaran 19-39 tahun.

Dibalik potensi sumber daya manusia yang dimiliki, perusahaan di indonesia memiliki tantangan dalam mengelola sumber daya manusia khususnya generasi $\mathrm{Y}$ atau milenial. Tantangan terbesar Perusahaanperusahaan masa kini adalah bagaimana cara menjaga, mempertahankan serta menekan intensi turnover. Menurut Zeffane (2003) turnover intention adalah kecenderungan atau niat karyawan untuk berhenti bekerja dari pekerjaannya. Intensi adalah niat atau keinginan yang timbul pada individu untuk melakukan sesuatu, sementara turnover adalah berhentinya atau penarikan diri seseorang karyawan dari tempat bekerja.

Faktor yang dapat mempengaruhi kinerja karyawan yaitu pengembangan karir. menurut Handoko (2008) mengemukakan bahwa pengembangan karir merupakan upaya-upaya yang dilakukan pribadi seorang karyawan untuk mencapai suatu rencana karir. Pada dasarnya pengembangan karir berorientasi pada perkembangan perusahaan / organisasi dalam menjawab tantangan bisnis di masa mendatang. Setiap organisasi harus menerima kenyataan, bahwa ekstensinya di masa depan tergantung pada
SDM yang kompetitif sebuah organisasi akan mengalami kemunduran dan akhirnya dapat tersisih karena ketidakmampuan menghadapi pesaing. Kondisi seperti itu mengharuskan organisasi untuk melakukan pembinaan karier pada pekerja, yang harus dilaksanakan secara berencana dan berkelanjutan. Dengan kata lain, pembinaan karier adalah salah satu kegiatan menejemen SDM, harus dilaksanakan sebagai kegiatan formal yang dilakukan secara terintegrasi dengan kegiatan SDM lainnya.

Akan tetapi tidak semua perusahaan memikirkan bahwa pengembangan karir karyawan adalah sesuatu hal yang harus dipikirkan, karena salah satu yang mendasari kemajuan dan perkembangan perusahaan di pengaruhi oleh pengembangan karir karyawan-karyawannya. Agar pengembangan karir karyawan dapat dipenuhi oleh perusahaan, perusahaan harus memiliki personalia yang baik dalam menilai kinerja karyawannya, sehingga karyawan berlomba-lomba untuk menghasilkan kinerja yang baik agar bias mendapatkan reward berupa pengembangan karir.

Dari penelitian awal yang dilakukan dengan mewawancarai beberapa orang karyawan PT. TEY, ditemukan beberapa faktor yang sedang menjadi isu di dalam perusahaan yang kemungkinan berpengaruh 
terhadap besarnya turnover yang terjadi di PT. TEY. Dari beberapa isu tersebut yang paling menonjol dan yang menimbulkan ketidakpuasan karyawan yaitu pengembangan karir karyawan. Adapun tujuan penelitian ini adalah untuk mengetahui apakah pengembangan karir berperan penting bagi intensi turnover pada karyawan generasi milenial di PT. TEY

\section{METODE}

Penelitian ini dilakukan di PT TEY dengan subjek karyawan generasi milenial sebanyak 95 orang. Metode yang dilakukan adalah dengan metode pengisian kuisioner yang diisi oleh subjek penelitian. Hasil yang didapat dari kuisioner diolah dengan menggunakan analisis korelasi, yaitu regresi sederhana.

\section{HASIL}

Tabel 1. Hasil analisis data

\begin{tabular}{|c|c|c|c|c|c|}
\hline \multirow[b]{2}{*}{ Model } & \multicolumn{2}{|c|}{$\begin{array}{c}\text { Unstandardized } \\
\text { Coefficients }\end{array}$} & $\begin{array}{c}\text { Standardize } \\
\mathrm{d} \\
\text { Coefficients }\end{array}$ & \multirow[b]{2}{*}{$\mathrm{t}$} & \multirow[b]{2}{*}{ Sig. } \\
\hline & B & Std. Error & Beta & & \\
\hline $\begin{array}{ll}1 & \text { (Constant } \\
& \text { ) }\end{array}$ & 68.445 & 9.294 & & 7.365 & .000 \\
\hline PK & .856 & .085 & -.849 & .565 & .000 \\
\hline
\end{tabular}

Dari analisis data yang dilakukan, ditemukan hasil nilai signifikansi $\mathrm{p}=$ $0.000 \quad(\mathrm{p}<0.05) . \quad$ Sehingga dapat disimpulkan bahwa terdapat korelasi yang sangat signifikan antara pengembangan karir dan intensi turnover pada karyawan.

\section{DISKUSI}

Dari hasil penelitian tentang pengembangan karir pada karyawan millenial di PT TEY didapatkan hasil bahwa terdapat korelasi yang sangat signifikan antara pengembangan karir dan intensi turnover pada karyawan. Hal ini menunjukkan pentingnya pengembangan karir bagi karyawan. Hal ini sejalan dengan yang dikemukakan oleh Harianja (2002), bahwa, bila seorang karyawan merasa pengembangan karirnya terhambat dan tidak berkembang sehingga tujuan karirnya tidak mungkin dicapainya dalam perusahaan tersebut maka karyawan tersebut mungkin tidak akan memiliki semangat kerja yang tinggi, tidak termotivasi untuk bekerja, dan bahkan akan berkeinginan untuk mengundurkan diri atau keluar dari perusahaan.

Pengembangan karir sebagai derajat persepsi karyawan tentang adanya program perencanaan karir untuk membantu anggotanya mencapai tujuan karir mereka. 
Kepercayaan pada organisasi memiliki pengaruh negatif terhadap tunrover intention. Penelitian yang sama juga dilakukan oleh Hafiz dkk (2016) dengan judul pengaruh pengembangan karir terhadap turnover intention pada karyawan PT BFI Finance, menemukan bahwa terdapat pengaruh antara pengembangan karir dengan intensi turnover.

Berdasarkan hasil penelitian yang diperoleh, penulis mencoba memberikan beberapa saran yang diharapkan bisa menjadi bahan pertimbangan, sebagai berikut :

a. Bagi instansi

Diharapkan untuk lebih memperhatikan pengembangan karir karyawan, agar intensi turnover dapat berkurang

b. Bagi karyawan

Diharapkan setiap karyawan mau untuk meningkatkan pengembangan karir, seperti mengikuti pelatihan-pelatihan untuk meningkatkan kemampuan atau potensi diri.

\section{DAFTAR PUSTAKA}

De Meuse, Kenneth P, Mlodzik, Kevin J. 2010. A second look at generational differences in the workforce: implication for $\mathrm{HR}$ and talent management. Korn/Ferry Leadership and Talent Consulting 33(2): 51-58.

Dessler, G. (2008). Human Resource Managemen. Edisi sebelas, New Jersey: Pearson Education, Inc.

Hafiz. J., Parizade. B., dan Hanafi. A. (2016). Pengaruh Pengembangan Karir Terhadap Keinginan Berpindah (Turnover Intention). Jurnal Ilmiah Manajemen Bisnis dan Terapan Unsri. 13(2). 325-326.

Handoko, T. Hani. (2008). Manajemen Personalia \& Sumber Daya Manusia. Edisi Kedua. Yogyakarta: Universitas Gadjah Mada Yogyakarta

Harianja. 2002. Manajemen Produksi Dan Operasi. Jakarta : PT.Gramedia Widiasarana Indonesia

Lyons, A. C. (2004). A Profile of Financially At-Risk College Students. The Journal of Consumer Affairs, 38, 56-80.

Mathis, R. L \& Jackson. J. (2011). Human Resource Management (edisi 10). Jakarta : Salemba Empat

Mobley. W. A. (1996). Pergantian Karyawan Sebab Akibat dan Pengendaliannya. Terjemahan Jakarta: PT Pustaka Binaman Pressido.

Mondy, R, W. (2008). Manajemen Sumber Daya Manusia. Jakarta: Erlangga.

Putra, Yanuar Surya. (2016). Theoritical Review: Teori Perbedaan Generasi. Among Makarti, Vol 9 No.18, 123-134.

Wahyuni. A. S, Zaika. Y, dan Anwar. R. (2014). Analisis faktor-faktor mempengaruhi Turnover Intention (keinginan berpindah ) karyawan pada perusahaan jasa konstruksi. Jurnal Rekayasa Sipil. 8(2). 20-23.

Zeffane, R. M. (1994). Understanding employee turnover: The need for a contingency approach. International Journal of Manpower. 15. 22-37. 